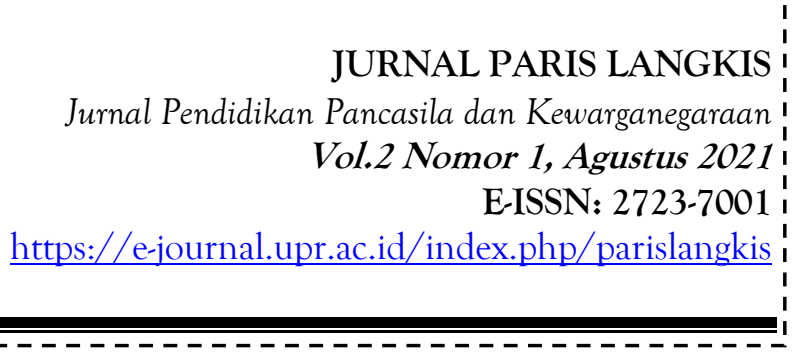

\title{
IMPLEMENTASI CORPORATE SOCIAL RESPONSIBILITTY (CSR) PT TUNGGAL PERKASA PLANTATIONS DI INDRAGIRIHULU
}

\author{
Rezty Karina Virnandhita ${ }^{1}$, Dadang Mashur ${ }^{2}$ \\ Fakultas Ilmu Sosial dan Ilmu Politik Universitas Riau \\ Kampus Bina Widya Km 12,5 Simpang Baru Pekanbaru 28293 \\ Email:Reztykarinaa@gmail.com,Dadangmashur@lecturer.unri.ac.id
}

\begin{abstract}
Abstrak
Untuk meningkatkan kualitas dan kuantitas masyarakat, tentunya dengan meningkatkan pendapatan, maka dengan itu PT Tunggal Perkasa Plantations memberikan program CSR yang nantinya sangat membantu dalam meningkatkan perekonomian masyarakat Indragiri Hulu. Kondisi sosial ekonomi masyarakat di Indragiri Hulu menengah kebawah dan sebagian juga merupakan karyawan PT Tunggal Perkasa Plantations dengan penghasilan yang tidak menentu dan tingginya angka pengangguran Dengan hadirnya program CSR diharapkan dapat meningkatkan taraf perekonomian serta mengurangi pengangguran khusunya pemuda desa setempat. Tujuan penelitian ini adalah untuk mengetahui Bagaimana implementasi Corporate Social Responsibillity PT Tunggal Perkasa Plantations terhadap masyarakat dan untuk mengetahui Bagaimana faktor penghambat dalam membantu sumber daya masyarakat. Untuk menjawab permasalahan tersebut penulis menggunakan metode penelitian kualitatif dengan pendekatan dekskriptif. Dalam penelitian kualitatif ini penulis menggunakan Teknik pengumpulan data dengan observasi, wawancara dan dokumentasi kemudian di analisis berdasarkan masalah penelitian. Konsep teori yang di gunakan adalah teori Wahyudi mengenai Implementasi CSR. Hasil penelitian ini ditemukan bahwa Implementasi CSR PT Tunggal Perkasa Plantations di Indragiri Hulu belum terimplemensi dengan baik dan belum maksimal dalam pelaksanaanya dikarenakan masih ditemukan faktor penghambat yaitu komunikasi dan partisipasi masyarakat yang rendah. Hal ini menyebabkan pengelolaan program tidak sesuai dengan target yang sudah ditentukan.
\end{abstract}

Kata Kunci: Corporate Social Responsibillity; Implementasi; Masyarakat

\section{Abstract}

To improve the quality and quantity of the community, of course, by increasing income, PT Tunggal Perkasa Plantations provides a CSR program which will be very helpful in improving the economy of the people of Indragiri Hulu. The socioeconomic conditions of the people in Indragiri Hulu are middle to low and some are also employees of PT Tungral Perkasa Plantations with uncertain income and high unemployment. The purpose of this study was to find out how the implementation of Corporate Social Responsibility of PT Tungral Perkasa Plantations to the community and to find out how the inhibiting factors were in helping community resources. To answer these problems the author uses a qualitative research method with a descriptive approach. In this qualitativeresearch the writer usesdata collection techniques with observation, interviews and documentation then analyzed based

\section{Paris Langkis}

Vol.2 Nomor 1, Agustus 2021 
on research problems. The theoretical concept used is Wahyudi's theory of CSR implementation. The results of this study found that the implementation of PT Tunggal Perkasa Plantations' CSR in Indragiri Hulu had not been implemented properly and had not been maximized in its implementation because there were still inhibiting factors, namely communication and low community participation. This causes the program management is not in accordance with the targets that have been determined.

Keywords. Corporate Social Responsibility; Implementation; Societysibility

\section{A. PENDAHULUAN}

Sebuah Perusahaan yang menginginkan kemakmuran dan perubahan jangka panjang tidak akan efektif tanpa memperhatikan etika bisnis. Selain itu, sejumlah masalah sosial perlu dipertimbangkan, seperti bagaimana keputusan memengaruhi lingkungan, karyawan, dan pelanggan. Istilah yang paling umum adalah tanggung jawab sosial, yang mengacu pada filosofi, kebijakan, prosedur dan tindakan yang tujuan utamanya adalah untuk meningkatkan kesejahteraan masyarakat. Singkatnya, dunia bisnis harus menemukan keseimbangan antara melakukan hal yang benar dan melakukan hal yang baik. Perusahaan memiliki banyak tanggung jawab terhadap pelanggan, karyawan, investor, dan masyarakat pada umumnya.

Peraturan perundang-undangan yang mengatur tentang pengertian CSR antara lain Undang- undang Penanaman Modal (UU PM) Nomor 25 Tahun 2007, Undang-undang Perseroan Terbatas (UUT) Nomor 40 Tahun 2007 , Undang-undang BUMN (UU BUMN) Nomor 19 Tahun 2003, dan Peraturan Daerah Riau Nomor 1 Tahun 2019 tentang Corporate Social Responsibillity (CSR). Pasal 15b UU PM menggunakan istilah tanggung jawab sosial. Hal ini diidentifikasi sebagai tanggung jawab tunggal dari semua perusahaan investasi untuk menghormati lingkungan, nilai-nilai, peraturan dan budaya masyarakat dan untuk terus membangun hubungan yang harmonis dan seimbang. . Oleh karena itu, Pasal 1 ayat 3 UUPT mendefinisikan tanggung jawab sosial perusahaan sebagai komitmen perusahaan untuk berpartisipasi dalam pembangunan ekonomi untuk meningkatkan kualitas kehidupan dan lingkungan untuk kepentingan masyarakat perusahaan itu sendiri. Dari masyarakat pada umumnya.

Program Corporate Social Responsibillity yang diberikan saat ini lebih ditekankan untuk ke Pemuda sebagai Starter mereka dalam memulai bisnis sehingga timbul keinginan untuk berusaha dan menghasilkan pemasukan. Program ini ditujukan untuk pemuda karena pemuda merupakan generasi milenial dimana mereka bisa berkembang dan memiliki potensi lebih banyakuntuklebih maju dalam berkarir, dalam programinisamahalnyauntukmelatih pemuda tersebut dalam berbisnis dari hal yang Kecamatanil. Sehingga nantinya jika program ini berjalan dengan lancar mereka bisa mengembangkan ilmu yang mereka dapat dalam memulai bisnis ini serta melanjutkan bisnisnya. Keuntungan Corporate Social Responsibillity ini bagi perusahaan yaitu untuk mngurangi kenakalan di Perusahaan seperti pencurian buah sawit dan berhubungan baik antara Perusahaan dan Masyarakat Ring satu. Namun, Program inipun memiliki kelebihan dan kekurangan yakni kelebihannya dapat langsung menyentuh masyarakat tanpa harus ada perantara seperti petinggi desa, sedangkan kekurangannya yaitu faktor keberhasilan dari program yang sudah diberikan perusahaan tergantung pada kemauan dan semangat pemuda dalam mengolah barang yang sudah diberikan oleh perusahaan.

Adapun rumusan dari penelitian ini adalah Bagaimana implementasi Corporate Social Responsibillity PT Tunggal Perkasa Plantations terhadap masyarakat dan Bagaimana faktor penghambat Corporate Social Responsibillity PT Tunggal Perkasa Plantations dalam membantu sumber daya

\section{Paris Langkis}

Vol.2 Nomor 1, Agustus 2021 
masyarakat. Adapun tujuan dari penelitian ini adalah Untuk mengetahui implementasi Corporate Social Responsibillity PT Tunggal Perkasa Plantations terhadap masyarakat dan Untuk mengetahui faktor penghambat Corporate Social Responsibillity PT Tunggal Perkasa Plantations dalam membantu sumber daya masyarakat.

\section{B. KAJIAN TEORI}

\section{a. Implementasi}

Menurut Wahab Yulianti (2018:14) implementasi program yang dengan upaya pembuat kebijakan untuk mempengaruhi perilaku pemimpin relawan dan mengatur perilaku kelompok sasaran. Pelaksanaan meliputi penentuan kemungkinan akibat atau dampak yang berupa undang-undang, peraturan pemerintah, keputusan pengadilan dan kebijakan yang diambil oleh instansi pemerintah dalam kehidupan bernegara (Setiawan \& Saefulloh, 2019).

MenurutVanMeterdan Van Horn dalamJulianda(2013:16)implementasididefinisikan sebagai tindakan yang diambil oleh perseorangan, pejabat atau pemangku kekuasaan, pemerintah atau kelompok swasta untuk mencapai target yang diidentifikasi dalam ketetapan kebijakan.

Implementasi dapat dilihat dari berbagai perspektif dan pendekatan. Di antaranya adalah pendekatan terhadap masalah implementasi yang dikemukakan oleh Edward III dalam Mulyadi (2016:5859). Edward III mengusulkan empat elemen sebagai persyaratan utama untuk proses implementasi yang sukses yaitu:

1. Komunikasi, sebuah program hanya bisa dijalankan dengan benar bila terlihat jelas oleh penyelenggara. Hal ini berkaitan dengan proses penyediaan informasi, kejelasan informasi dan konsistensi informasi yangdisajikan.

2. SDM terdiri dari empat elemen: pekerja yang cukup (kuantitas dan kualitas), Informasi yang diperlukan untuk pengambilan keputusan, wewenang yang tepat untuk memenuhi kewajiban atau tanggung jawab, dan struktur yang diperlukan.

3. Sikap, disposisi atau perilaku pejabat atau agen merupakan tanggung jawab terhadap program.

4. Struktur organisasi memuat proses kerja birokrasi yang mengatur alur kerja dan melaksanakan kebijakan.

Grindle, (1980) dalam Haris (2017:212) berpendapat bahwa Implementasi kebijakan mengkaitkan sasaran kebijakan dan pencapaian dengan kinerja pemerintah. Ini adalah perspektif (Grindle,1980) dengan gagasan bahwasan misinya adalah membangun jaringan yang memungkinkan pencapaian sasaran kebijakan publik melalui kerja lembaga pemerintah yang membuat berbagai pihak yang berkepentingan (policy stakeholders), faksi politik terlibat. (Grindle, 1980).

Menurut Lane dalam Haris (2017:212) implementasi sebagai konsep dapat dibagi menjadi dua bagian. Pertama, implementation $=\mathrm{F}$ (Intention, Output, Outcome) . Menurut definisi ini, kinerja adalah karakteristik yang mencakup niat dan tujuan, hasil dan hasil produk. Kedua, implementasinya adalah persamaan fungsional dari implementation $=\mathrm{F}$ (Policy, Formator, Implementor, Initiator, Time). Fokus utama dari kedua fungsi ini adalah kebijakan itu sendiri. Oleh karena itu, ini adalah hasil yang dicapai dan dilakukan oleh implementor dalam periode waktu tertentu.(Sabatier, 1986).

\section{Paris Langkis}

Vol.2 Nomor 1, Agustus 2021 


\section{b. Corporate Social Responsibillity (CSR)}

Farmer dan Hougue dalam Rahayu (2021:14) lebih menekankan CSR merupakan upaya perusahaan untuk memungkinkan masyarakat memberikan apa yang mereka inginkan. Dengan cara ini, perusahaan tidak hanya melayani barang dan melayani pembeli barang, tetapi juga membantu memecahkan masalah masyarakat.

CSR merupakan inisiatif untuk meningkatkan kesejahteraan masyarakat setempat melalui kegiatan kewirausahaan. Tapi itu bukan amal, ini adalah strategi perusahaan utama individu atau kelompok yang mungkin atau dapat mempengaruhi berbagai keputusan, kebijakan atau kegiatan organisasi. (Mardikanto, 2014:130)

Totok Mardikanto (2014) dalam Ramona (2017) mengatakan implementasi Corporate Social Responsibillity didasarkan pada prinsip-prinsip sebagai berikut:

1. Prinsip kepatuhan hukum

2. Kepatuhan terhadap hukum adat internasional

3. Menghormati pemangku kepentingan

4. Prinsip transparansi

5. Menghormati hak asasi manusia.

Pada tahun 2002, Global Compact Initiative menegaskan bahwa tujuan perusahaan adalah mencari keuntungan (profit), meningkatkan kesejahteraan orang (people) dan menjamin keberlanjutan kehidupan (planet), CSR I menegaskan kembali tiga P sebagai ketiga pilar tersebut. (Azhari, 2015:35).

Dalam implementasinya secara ringkas bentuk dari CSR ini dapat dikelompokan menjadi empat bentuk, yaitu (Wahyudi, 2011:62) yaitu : (a)Pengelolaan lingkungan kerja secara baik, termasuk di dalamnya penyediaan lingkungan yang aman dan nyaman, system kompensasi yang layak dan perhatian terhadap kesejahterahan karyawan dan keluarganya. (b) Kemitraan antara perusahaan dengan masyarakat, khususnya masyarakat lokal. Kemitraan ini diwujudkan secara umum dalam program community development untuk membantu peningkatan kesejahterahan umum masyarakat setempat dalam kurunwaktuyangcukup panjang.

a. Penanganan kelestarian lingkungan.

b. Investasi sosial yang sering diartikan secara sempit sebagai "kegiatan amal perusahaan".

\section{Paris Langkis}

Vol.2 Nomor 1, Agustus 2021 
Gambar. 2.1.

Kerangka Berfikir

Implementasi Tanggung Jawab Sosial Peusahaan (CSR) PT. Tunggal Perkasa Plantations t di Indragiri Hulu

Fenomena:

1. Tidak kesesuaian nya kebutuhan dengan program perusahaan.

2. Masih minimnya dari segi skill SDM dalam pengelolaan program.

3. Kurangnya antusias masyarakat terhadap program yang diberikan

4. Tidak meratanya pembagian program CSR di setiap desa

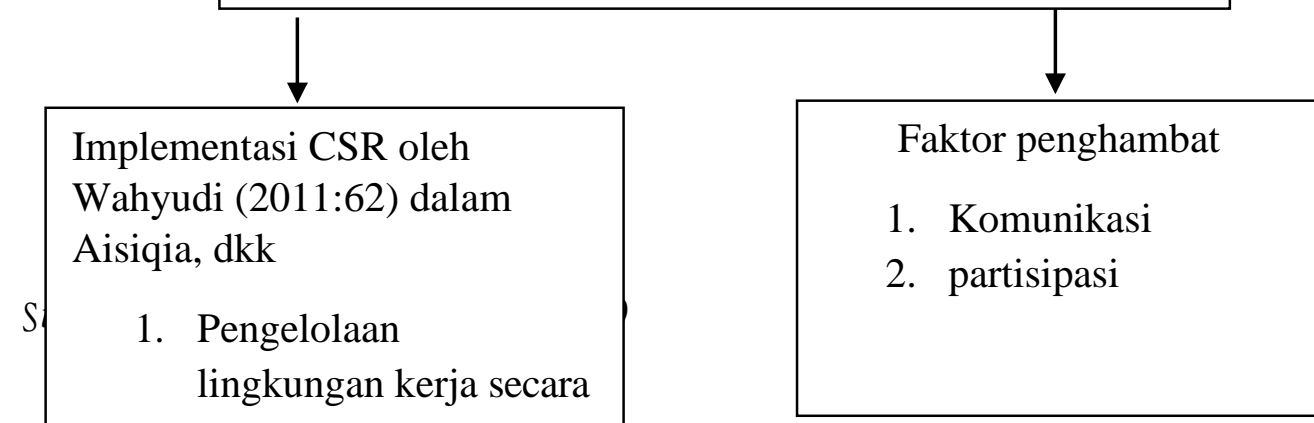
baik

2. Kemitraan antara perusahaan dengan masyarakat

3. Penanganan kelestarian lingkungan

4. Investasi sosial

\section{METODE PENELITIAN}

Jenis penelitian yang digunakan dalam penulisan penelitian ini adalah penelitian deskriptif dengan menggunakan pendekatan kualitatif, Jenis penelitian yang digunakan dalam penulisan penelitian ini adalah penelitian deskriptif dengan menggunakan pendekatan kualitatif. dilakukan dengan menggunakan sumber data utama atau primer dan data sekunder dengan menggunakan teknik pengumpulan data yaitu: 


\section{Dokumentasi}

Menurut Kamus Besar Bahasa Indonesia, dokumen ditulis, dicetak atau direkam untuk dijadikan sebagai bukti atau keterangan. Dokumentasi adalah metode pengumpulan data penelitian tentang masalah dan variabel dalam bentuk memo atau metode pengambilan data dengan merekam data yang ada. Adapun dokumentasi yang dilakukan peneliti adalah berupa tulisan, gambar, file,catatan, dan arsip yang berhubungan dengan Implementasi Corporate Social Responsibillity (CSR) PT Tunggal Perkasa Plantations di Kabupaten Indragiri Hulu.

\section{Observasi}

Strisno Hadi (1989) berpendapat bahwa observasi merupakan proses kompleks yang terdiri dari beberapa proses biologis dan psikologis. Dua diantaranya yang terpenting adalah proses observasi dan memori (Sugiyono,2013:203). Pengamatan dilaksanakan untuk mengamati permasalahan mengenai Implementasi Corporate Social Responsibillity (CSR) PT Tunggal Perkasa Plantations di Kabupaten IndragiriHulu.

\section{Wawancara}

Wawancara merupakan metode pengumpulan data langsung dan langsung untuk tanya jawab antara peneliti dan narasumber yakni mengenai Implementasi Corporate Social Responsibillity (CSR)PTTunggal Perkasa Plantations di Kabupaten Indragiri Hulu.

\section{D.HASIL DAN PEMBAHASAN}

Partisipasi masyarakat sangat dibutuhkan untuk terwujudnya program CSR yang sudah diberikan oleh pihak perusahaan yang dilakukan secara akumulatif sehingga semakin tinggi nya keterampilan serta kompentensi yang dimiliki masyakat yang membuat tingkat partisipasinya pun meningkat.Untuk pihak perusahaan sudah berusaha semaksimal mungkin untuk ikut serta dalam mewujudkan program CSR ini, dengan memberi dukungan dan bantuan baik berupa tenaga maupun dana yang dikeluarkan untuk membantu masykarat agar lebih terampil dalam mengembangkan sarana dan prasarana yang didapat dari pihak perusahaan, sehingga tidak hanya mampu mengelola hasil yang didapat namun juga mampu menciptakan lapangan pekerjaan dari keterampilan serta kompetetensi yang dimiliki masyarakat tersebut.

Dalam program ini ketua karang taruna berperan penting dalam mengelola program agar berjalan dengan lancar meskipun tidak sedikit beliau mengeluarkan uang hanya untuk membantu terwujudnya program, walaupun semua kebutuhan pakan ikan sudah terpenuhi tidak jarang mereka mengalami kekurangan yang mengakibtakan ketua karang taruna itu sendiri mengeluarkan uang pribadi nya untuk memenuhi kebutuhan program. Beliau melakukan hal itu karena merasa segan terhadap pihak perusahaan yang sudah banyak membantu dalam hal pemberdayaan masyarakat itu sendiri.

perusahaan sudah berusaha maksimal untuk memberikan program yang sifatnya Tanggung Jawab perusahaan yang sudah tertera dalam Undang-undang No. 40 Tahun 2007, tentang Perseroan Terbatas, Bab V, Pasal 74. Dalam pasal tersebut dijelaskan Corporate Social Responsibillitydari perusahaan atas eksistensinya dalam kegiatan bisnis, namun tidak sedikit masyarakat mengeluh bahwa kegiatan berupa program setiap tahunnya itu tidak berjalan dengan semestinya. Maka dari itu masyarakat kurang antusias

\section{Paris Langkis}

Vol.2 Nomor 1, Agustus 2021 
dalam hal ini, akibat sudah sering merasa bahwa program yang diberikan tidak pernah terealisasikan dengan baik. Tetapi,bagi pihak perusahaan mereka juga tidak pernah hilang akal untuk memberikan yang terbaik untuk masyarakatnya, walaupun respon masyarakat tidak begitu sesuai dengan ekspetasi yang sebelumnya sudah mereka rencanakan.

Hal ini terjadi karna kurangnya komunikasi sehingga terjadinya kesalah pahaman, baik dari prosedur program, dana dan material program, tujuan program, serta kelompok sasaran dari program.maka dari itu sebagaian masyakarat tidak mendukung penuh dan ikut berkontribusi dalam program yang menyebabkan tidak berhasilnya sehingga pihak perusahaan pun merasa bahwa yang sudah di upayakan untuk masyarakat sia-sia. Selain itu permasalahan yang menjadi konflik yaitu kemauan masyakat dalam bekerja sama sehingga timbulnya rasa ketidak adilan dalam pembagian kerja sehingga kurang maksimal hasil dari program. Menurut salah satu anggota karang taruna, permasalahan mereka dalam pembagian tugas yang tidak terlalu jelas diantara masing masing anggotanya, yang mengakibatkan timbulnya kebingungan untuk melakukan pekerjaan yang mana terlebih dahulu.

Perusahaan bertanggung jawab atas kondisi lingkungan sekitar perusahaan dengan mengikuti peraturan kementrian lingkungan yang sudah menjadi standarisasi dalam pengelolaan lingkungan suatu perusahaan. Dengan begitu mereka sangat memperhatikan segala sesuatu yang berkaitan dengan lingkungan baik itu udara, air dan tanah yang sangat berperanguh dalam kehidupan masyarakat sehari hari.

Walaupun begitu, masyarakat pun tidak sungkan untuk memberi tahu bahwasannya jalan yang merupakan fasilitas umum mengalami kerusakan yang di akibatkan kendaraan perusahaan rusak, maka masyarakat meminta untuk berkontribusi dalam perbaikan jalan tersebut demi kenyaman Bersama. Dan sampai sejauh ini perusahaan berusaha keras untuk memenuhi permintaan masyarakat.

setiap tahunnya pihak perusahaan memang memberikan bantuan CSR kepada masysrakat. Dimana mungkin tidak semua kegiatan akan di bantu, namun ada beberapa dari sekian kegiatan. Pihak perusahaan juga lebih menekankan pada kegiatan yang melibatkan karyawan PT itu sendiri, seperti kegiatan Qurban, pesta rakyat dan lain sebagainya.

Namun di Kecamatan Pasir Penyu tepatnya di desa Candirejo terdapat bangunan yang dulunya merupakan tempat yang digunakan masyarakat untuk menyelenggarakan berbagai acara termasuk acara adat daerah setempat yakni Gedung Balai Adat. Ini merupakan salah satu bentuk kepedulian PT Tunggal Perkasa Plantations terhadap kebudayaan masyakrat dengan menghibahkan lahan nya di Kawasan Pasir Penyu pada tahun 2001, yang salah satunya merupakam lahan dimana tempat berdirinya Gedung Balai Adat ini.

\section{E. KESIMPULAN}

Hasil penelitian dan analisa Implementasi Corporate Social ResponsibillityPeusahaan (CSR) PT Tunggal Perkasa Plantations di Kabupaten Indragiri Hulu yang sudah penulis lakukan memberikan beberapa kesimpulan dan saran antara lain :

a. Implementasi Corporate Social Responsibillity (CSR) PT Tunggal Perkasa Plantations di Kabupaten Indragiri Hulu belum terimplemensi dengan baik dan belum maksimal dalam pelaksanaanya. Hal ini hasil dari program yang tujuannya untuk memberdayakan masyarakat yang diinginkan belum terealisasi dengan baik. Permasalahan ini terjadi

\section{Paris Langkis}

Vol.2 Nomor 1, Agustus 2021 
ditandai dengan beberapa indikator yaitu dari kurangnya komunikasi antara masyarakat dan perusahaan yang menyebabkan mis komunikasi, sehingga harapan masyarakat tidak sesuai dengan yang diberikan oleh perusahaan dan kurangnya rasa partisipasi masyarakat yang menyebabkan program tidak terkelola dengan sempurna, yang berpengaruh besar pada perkembangan serta hasil akhir suatu program.

b. Faktor-faktor yang penghambat Implementasi Corporate Social Responsibillity (CSR) PT Tunggal Perkasa Plantations di Kabupaten Indragiri Hulu, ada dua yaitu :komunikasi dan partisipasi. Adanya dua hambatan ini menjadikan CSR perusahaan ini belum terimplementasi dengan baik dan optimal. Hal yang menjadi hambatan terbesar ialah partisipasi masyarakat dalam mengolala program untuk terus menghasilkan dangan mengembangkan program yang dibuat agar lebih berkembang dan membantu perekonomian masyarakat sekitar.

\section{F. SARAN}

Berdasarkan hasil penelitian dan pembahasan yang sudah diuraikan, berikut penulis uraikan beberapa saran yang diharapkan menjadikan masukan dan pertimbangan Tanggung Jawab Sosial Perusahaan PT Tunggal Perkasa Plantations,, terkhususnya kepada masyarakat dan pembaca lainnya. Berikut saran yang penulis berikan yaitu :

1. Agar Implementasi Corporate Social Responsibillity (CSR) PT Tunggal Perkasa Plantations di Kabupaten IndragiriHulu dapatberjalan dengan baik dan maksimal maka sekiranya dapat dilakukan beberapa hal sebagai berikut (1) Perlunya komunikasi yang baik antara perusahaan dan masyarakat untuk mencari program yang tepat untuk di laksanakan. (2) perlunya pasrtisasi dan semangat yang tinggi dari masyarakat dalam melaksanakan dan mengelola suatu program, dibutuhkan masyarakat yang kreatif untuk menciptakan inovasi baru dalam program agar tidak cepat menyerah dan merasa bosan.

2 Hal-hal yang dapat dilakukan untuk meminimalisir faktor-faktor penghambat Implementasi Corporate Social Responsibillity (CSR) PT Tunggal Perkasa Plantations di Kabupaten Indragiri Hulu, antara lain yaitu :(1) Perusahaan dan masyarakat harus selalu mengadakan pertemuan untuk membahas hal hal apa saja yang harus dilakukan untuk terealisasinya suatu program, harus berembuk saling mendengarkan pendapat serta keluhan satu sama lain, juga harus transparan terhadap pihak perusahaan. (2) Masyarakat seharusnya lebih berpatisasi dan semangat antusias terus terhadap apa yang di usulkan oleh perusahaan sehongga masyarakat juga lebih produktif dalam mengembangkan program. Membuat inovasi terbaru bagaimana cara mengolal program bioflog ikan lele dengan benar agar menghasilkan ikan yang berkualitas dan bioflog berhasil.

\section{DAFTAR PUSTAKA}

Sugiyono. 2007. Metode Penelitian Pendidikan Pendekatan Kuantitatif, Kualitatif, dan REDD. Bandung: Alfabeta.

Sugiyono. 2011. Metode Penelitian Kombinasi (Mixed Methods). Bandung: Alfabeta. Sugiyono. 2016. Metode Penelitian Kuantitatif, Kualitatif, dan REDD. Bandung: Alfabeta.

\section{Paris Langkis}

Vol.2 Nomor 1, Agustus 2021 


\section{Dokumen :}

Peraturan Pemerintah No. 47 Tahun 2012 Tanggung Jawab Sosial dan Lingkungan Perseroan Terbatas.

Peraturan Daerah Kota Provinsi Riau Nomor 1 Tahun 2019 tentang Corporate Social Responsibillity

\section{Jurnal :}

Al- Muhajir Haris \& Eko Priyo Purnomo. (2016). Implementasi CSR (Corporate Social Responsibillity) PT Agung Perdana Dalam Mengurangi Dampak Kerusakan Lingkungan (Studi Kasus Desa Padang Loang, Seppang dan Desa Bijawang Kecamatan Ujung Loe Kab. Bulukumba. 257-287. https://doi.org/10.1016/b978.012473345.9/50015.5

Aryawan, M., Rahyuda, I. K., \& Ekawati, N. W. (2017). Pengaruh Faktor Corporste Social Responsibility (Aspek Sosial, Ekonomi , dan Lingkungan ) Terhadap Citra Perusahaan. 6(2), 604- 633.

Devi Yulianti. (2013). Implementasi Program Kemitraan Dalam Corporate Social Responsibillity (CSR) Melalui Pemberdayaan Masyarakat Untuk Mewujudkan Pembangunan Kesejahteraan. 53(9), 1689-1699.

Dewi, S. (2017). Implementasi CSR di dalam membantu peningkatan kesejahteraan sosial ekonomi masyarakat. 1-66.

Hatane Semuel, \& Elianto Wijaya. (2008). Corporate Social Responsibillity, Purchase Intention Dan Corporate Image Pada Restoran Di Surabaya Dari Perspektif Pelanggan. Jurnal Manajemen Pemasaran, 3(1), 35-54. Retrieved from

http://puslit2.petra.ac.id/ejournal/index.php/mar/article/view/18079

Intan Aisyiah Aisiqya, Choriul Saleh, M. H. (n.d.). Corporate Social Responsibillity (CSR) Sebagai Upaya Pemberdayaan Masyarakat Sekitar Pabrik Gula (Studi pada PTPN X Persero PG. Kremboong Sidoarjo). 1(5), 881-889.

Julianda, H. (2013). Implementasi Corporate Social Responsibillity Pada PT Maruki Internasional Indonesia. 1(1), 29-35. https://doi.org/10.33649/pusaka.v1i1.10

Mapisangka, A. (2009). Implementasi CSR terhadap Kesejahteraan Hidup Masyarakat. JESP Vol.

1, No. 1, 1(1), 40-47.

(Maulania, 2019)Maulania, M. I. (2019). Peran Corporate Social Responsibility ( Csr ) Pt . Inalum Terhadap Pengembangan. 7(1), 51-64.

Primady, G. R. (2018). Pengaruh Corporate Social Responsibillity dan Profitabilitas Terhadap Nilai Perusahaan Dengan Kepemilikan Manajerial Sebagai Variabel Pemoderasi. 10(1). https://doi.org/10.30813/jab.v10i1.985

Ramona, S. (2017). Pengaruh Corporate Social Responsibillity Terhadap Nilai Perusahaan Dengan Profitabilitas Sebagai Variabel Moderating (Studi Empiris Perusahaan Sektor Pertambangan yang Terdaftar di Bursa Efek Indonesia Periode 2011-2015). Jurnal Fakultas

\section{Paris Langkis}

Vol.2 Nomor 1, Agustus 2021 
Ekonomi Prodi Akuntansi Universitas Pasir Pengaraian, 1-14.

Sari, W. A., Handayani, S. R., \& Nuzula, N. F. (2016). Pengaruh Pengungkapan Corporate Social Responsibillity Terhadap Kinerja Keuangan Dan Nilai Perusahaan ( Studi Komparatif pada Perusahaan Multinasional yang Terdaftar di Bursa Efek Indonesia dan Bursa Malaysia Tahun 2012. 2015 ). Jurnal Administrasi Bisnis (JAB), 39(2), 74-83.

Satmoko, M. P. (2016). Kontribuksi Corporate Social Responsibillity (CSR) PT Tirta Investama (AQUA) Manglikejiwan Terhadap Kehidupan Sosial dan Ekonomi Masyarakat Kelurahan Kejiwan Kecamatan Wonosobo Kabupaten Wonosobo Provinsi Jawa Tengah.

syainatul Wida. (2017). Analisis Impelementasi Corporate Social Responsibillity (CSR) Terhadap Peningkatan Kesejahteraan Masyarakat Dalam Perspektif Ekonomi Islam (Studi Pda PT Telkom Majapahit Bandar Lampung). 2(2), 65-72. https://doi.org/DOI:

Wahyudi, Isa., \& Azheri, Busyra. (2008) Corporate Social Responsibility, Prinsip, Pengaturan dan Implementasi. Malang, In Trans Institute dan Ispire.

Wardie, J., \& Taufik, E. N. (2017). Kajian Implementasi Program CSR Perusahaan Perkebunan Kelapa Sawit Kepada Masyarakat Di Kabupaten Kotawaringin Barat. 1(1), 18. https://doi.org/10.14710/agrisocionomics.v1i1.1637

K. Wong C, Fearon G. Philip, (2007), Understanding egovernment and egovernance: stakeholders, partnerships and CSR, Interna-tional Journal of Quality \& Reliability Management, Vol. 24 Iss 9 pp. 927943 